\title{
Location Attractiveness as a Major Factor in Museum Visitors' Choice and Satisfaction
}

\author{
Federica Codignola, Paolo Mariani \\ University of Milan-Bicocca, Milan, Italy
}

\begin{abstract}
This paper is intended to give a contribution to the debate on the functional relationship between the museum and the local territory; more specifically, the aim of this study is to understand the role of a museum location in attracting visitors and influencing their processes of choice and satisfaction. The study follows, in particular, a previous study conducted by Mariani and Mussini (2013) based on Fondazione di Venezia data, with a view to better contextualization level. Previous studies have examined the role of museums in enhancing the image of a destination and in attracting and conveying additional tourists' fluxes, arguing that although not all museums are a destination of choice for visitors, a great museum or a strong exhibition program still does represent a national and international attraction. This paper overturns this argument investigating whereas an appealing location (such as a tourist destination) can influence prospective visitors about the level of attractiveness of a pay cultural event taking place therein. A questionnaire was developed and data were collected at the Palazzo Ducale in Venice, Italy, in 2007, during the art exhibition "Venezia e l'Islam 829-1797”, via 501 face-to-face visitors interviews. The research model analyzes data through the conjoint analysis and the descriptive statistics. Results show that the exhibition location has been a relevant factor in influencing the visitors' decision process linked to the attendance of the event. Data show that, for the majority of visitors, the exhibition had been located elsewhere, they would not have visited it. Thus, an appealing location or a structured tourist destination may function as an attractive platform that may contribute to enforce the overall visitor's satisfaction with regard to his or her attendance to a cultural event. Furthermore, such a fact depends on specific objective variables (e.g., level of education, age), although no significant differences were reported between segments based on other socio-demographic characteristics such as sex. To conclude, arts and cultural managers should market and position cultural events in locations that can function as attractive, thus as emotionally driven experience consumption sites. Furthermore, they should consider both the cognitive and the emotional aspects of visitor's experience when designing and planning their events, as well as when assessing visitor's satisfaction. Cognitive and emotional aspects should be considered simultaneously when measuring visitors' satisfaction. In shaping visitors' satisfaction, emotions, such as the pleasure to be in a particular location, are more significant than cognitive aspects, such as the theme of the exhibition.
\end{abstract}

\footnotetext{
*Acknowledgments: The authors would like to thank "Fondazione di Venezia" for providing them with data used in the analysis. The usual disclaimers apply.

* Federica Codignola (F.C.) and Paolo Mariani (P.M.) share the final responsibility for this paper, however F.C. wrote sections 1, 2, and 6 and P.M. wrote sections 3, 4, and 5.

Federica Codignola, tenured assistant professor, School of Economics and Statistics, Department of Economics, Management and Statistics (DEMS), University of Milan-Bicocca, Milan, Italy.

Paolo Mariani, full professor, School of Economics and Statistics, Department of Economics, Management and Statistics (DEMS), University of Milan-Bicocca, Milan, Italy.

Correspondence concerning this article should be addressed to Federica Codignola, Piazza dell'Ateneo Nuovo, 1, DEMS, University of Milan-Bicocca, Milan, 20126, Italy.
} 
Keywords: cultural management, arts management, museum management, cultural event, museum attendance, visitor's satisfaction, location attractiveness, conjoint analysis

\section{Introduction}

The subject of museums in relationship to their local territory, communities, and economies appears to be of great interest from a theoretical perspective and form a practical point of view. In fact, taking into account cultural tourism, cultural economics, and urban planning studies, as well as managerial implications for museums, the current issue of museums and territories today results to be topical.

Earlier researches have mainly studied the role of museums in enhancing the image of a destination and in magnetizing and conveying supplementary tourists' fluxes. Furthermore, some authors have argued that, even though not all museums are a precise destination of choice for visitors, still, a recognizable and famous museum or a strong exhibition program may often represent and embody a national and international attraction.

The paper follows, in particular, a previous study conducted by Mariani and Mussini (2013) based on Fondazione di Venezia data, with a view to better contextualization level. The novelty of this paper is represented by the fact that the study overturns this argument. In fact, the paper investigates whether an appealing location (such as a tourist destination) can be regarded as an influencing factor that determines, in prospective visitors, the level of attractiveness of a pay cultural event taking place therein.

In order to answer such research question, this paper firstly reviews some literatures on visitor's satisfaction, perceived quality, emotional path, and consumer behavior. Secondly, this paper analyzes data collected through a questionnaire carried out at Palazzo Ducale in Venice, Italy, during the art exhibition “Venezia e l'Islam 829-1797”, via 501 face-to-face visitors interviews. Data analysis is conducted through the conjoint analysis and the descriptive statistics.

Results and conclusion will try to point out whether an exhibition location can be considered as a relevant factor able to influence the visitors during their decision making process linked to the attendance of the event. In the case of this study, the paper argues that if the exhibition had been located elsewhere, visitors would not have visited it. Taking into account such assumption, an appealing location or a well-structured tourist destination may then function as an attractive platform that can contribute to enforceing the overall visitor's satisfaction with regard to his or her attendance to a cultural event. Therefore, arts and cultural managers should position events in a location that can be perceived as an attractive one or as an emotionally-driven experience consumption site. In fact, in determining visitors' satisfaction, emotions, such as the enjoyment to be in a particular location, might be as significant as some cognitive aspects such as the theme of the exhibition, or even more determinant.

\section{Literature Review}

\section{Visitor's Satisfaction}

Previous studies have frequently observed the role of cultural events and cultural institutions in the attractiveness of a determined destination (a city or a definite area). Specifically, the majority of such studies have collectively examined the role of museums in reinforcing and regenerating the image of a place and in attracting and conveying additional tourists' fluxes. A number of studies argue that although not all museums are a destination of choice for visitors, still a great museum, an architecturally significant building, or a strong 
exhibition program do represent a national and international attraction. This paper overturns this argument. It investigates whether an appealing location such as a tourist destination can influence prospective visitors and the level of attractiveness of a pay cultural event that takes place therein. More precisely, this study examines whether location plays a role in the overall visitor's satisfaction and consumer behavior. In sum, the paper verifies whether an appealing location, thanks to its cognitive and emotional features, may function as an attractive platform for cultural events through which a visitor's satisfaction may influence his willingness-to-pay.

The function of marketing in cultural services and cultural tourism seems more and more relevant. Such fact is particularly evident considering the interest shown by numerous cultural and artistic subjects such as foundations, museums, or exhibitions in visitors' judgments and experience estimation and perceptions' relation to satisfaction.

Visitor's experience turns out to be a strategic idea in cultural marketing as tourists' satisfaction is frequently influenced by the overall involvement attained; they look for a full and complete experience that can bring entertainment, knowledge, and culture together. In order to realize complete and satisfactory experiences for visitors, museums realize a growing number of public-involving actions and supply a range of digital and non-digital tools. These circumstances are also developed in order to facilitate the educational experience, and to enhance the overall visitor involvement.

In this sense, the museum (within the exhibition) becomes an occasion for supplementary embellishment of visitors' appreciation (Colbert, 2003). Such background explains why museums and exhibitions offer a variety of different services (e.g., educational programs, bars, restaurants, bookshops, events, etc.) aimed to enhance the global experience in terms of accessibility and various significances transmitted to the visitors. Moreover, museums enforce the general tourism product of a destination by offering a set of emotions linked to a peculiar location and moment, which is frequently inaccessible somewhere else (Tuft \& Milne, 1999).

Museums then, contribute to the creation of a broad cultural structure aimed to spread experiences and knowledge (Herreman, 1998), and at the same time, supply "hereness" emotions (Kirchenblatt-Gimblett, 1998).

Among all these factors which clearly affect the visitor's satisfaction, the location of the museum appears therefore another significant element that deals with visitors' emotions and that may influence their level of satisfaction and their consumer behavior.

Marketing literature has extensively debated in consumer's satisfaction (among others: Belk \& Wallendorf, 1989; Gerson, 1994; Chakrapani, 1998). Although past literature has focused on observing satisfaction by estimating consumers' formulating of perceived quality from their assumptions, the latest literature has understood consumers' emotions as a main factor in generating satisfaction. Based on such assumption, this paper considers an additional determinant in generating visitor's satisfaction which is the "exhibition" here considered as a conveyor of cultural assets and products. Therefore, this study assimilates a new location-based theoretical path. In fact, despite the useful correlation that encloses expectations and perceived quality in order to measure visitor's satisfaction, this paper argues that participation and emotions are also relevant to cultural events, and that an attractive location positively influences both (participation and emotions).

Among all the various resources, benefits, and tools supplied by museums, taking into account emotional factors into the satisfaction's construct may result in some interest when assuming that the preponderance of benefits is founded on the visitors' involvement. An attractive location, such as a famous touristic destination, simultaneously represents an added value in the overall visitor's experience and affects museum visitors' emotions. 
Effectively, visits to cultural attractions and events are typically a minor activity and not the major incentive for visiting a destination (McKercher, 2004). Thus, considering a museum, an appealing location (such as a tourist destination) can influence prospective visitors and determine the level of attractiveness of a pay cultural event, such as an exhibition taking place therein.

In this paper, a particular type of cultural tourist will be taken into account: such profile views art and culture as an "extra" beside another principal motivation, which is represented by the attractive tourist destination (Silberberg, 1995).

Moreover, an attractive tourist destination represents, in visitors' mind, a particular level of emotion connected to enjoyment (Dolnicar, 2002). Taking into account visitor's satisfaction, previous literature underlines the outcome of service quality (Caldwell, 2002; Harrison \& Shaw, 2004), without taking into account emotions such as the enjoyment resulting from the exhibition's location.

In this paper, results of a survey are proposed in order to enlighten the creation of visitor's satisfaction from the relationship between cognitive opinions and affective opinions, and to demonstrate the role of positive emotions linked to the exhibition location when such location is represented by an appealing tourist destination. Empirical analysis performed in the Doge's Palace during the "Venice and Islam 829-1797" art exhibition held in Venice in 2007 (July 25-28, November, 2007) allows this study to formulate conclusions and establish managerial implications.

As said, the topic of visitor's satisfaction is extensively discussed in literature. First and foremost, the concept of satisfaction has been variously identified, which means that the concept itself is heterogeneous by its nature.

Conventionally, the concept was judged to be a cognitive condition, subjective to precedent perception, and had virtual nature because it is the consequence of the association between a subjective experience and a precedent base of reference (Churchill \& Surprenant, 1982; Oliver \& Desarbo, 1988). Lately, literature has agreed on the fact that a limited cognitive path would result inappropriately in shaping satisfaction's measuring standards. Moreover, some authors have underlined the requirement to value satisfaction through emotions (Philips \& Baumgartner, 2002; Wirtz \& Bateson, 1999). Moreover, Wirtz, Mattila, and Tan (2000) specifically emphasized the implications of taking into account emotions when observing consumer's satisfaction in relationship to services. Services, in fact, have an experiential nature.

For this reason, in this paper, instead of considering the exhibition as a product, the exhibition is viewed as a benefit provided by the museum. Moreover, for the purpose of this study, satisfaction will be viewed as the total evaluation of different aspects and elements of such benefit, but also as the sum of the emotions developed both by its cognitive and affective attributes.

The location of the exhibition is in fact a relevant part of the overall visitor's experience and when the location is an appealing and attractive tourist destination, this will affect the visitors' perceived quality, visitors' emotions, and the general level of satisfaction.

By assuming the cognitive path in order to observe satisfaction, literature recognizes the disconfirmation model of expectations (Oliver \& Swan, 1989). Such literature assesses that satisfaction has an active role in disconfirmation. At the same time, Oliver (1997) assessed that disconfirmation has an active role in an individual's realization and expectation. Therefore, an individual may be satisfied when he reaches expectation. At the same time, if a negative disconfirmation of an expectation brings non-satisfaction, a positive disconfirmation enhances satisfaction. In reaction to such theories that in the end agreed with assessing that 
consumer behavior is mainly connected to the good's service, function, and perceived quality, some literatures started to observe consumer behavior through the lens of emotions, despite their uncertain nature (Bagozzi, Gopinath, \& Nyer, 1999).

In order to prove that an appealing location of an exhibition affects visitor's satisfaction, both theoretical paths are useful. In fact, if visitors certainly evaluate the exhibition perceived quality, compare perceived quality and expectation, and pass through a confirmation or disconfirmation procedure in order to assess their satisfaction (cognitive path), they also evaluate through emotions if the exhibition attains or even surpasses expectation.

This paper argues that an appealing location is linked to perceived quality but also stimulates emotions. Therefore, an appealing location impacts visitor's satisfaction.

\section{Quality, Satisfaction, and Consumer's Behavior}

Predominantly, service and product quality studies focus on a cognitive approach (Vida \& Reardon, 2008) while satisfaction may be an emotional effect following experiences (Lee, Perick, \& Crompton, 2007). However, in order to measure quality and satisfaction, there are different paths: for instance, some literatures attempt to evaluate satisfaction taking into account particular features such as locations (Truong \& Foster, 2006). In order to overtake some theoretical issues that emerge when the evaluation of satisfaction is not distanced from the measurement of locations' features, it is impossible to observe the influence of every particular group' features on visitor satisfaction. Therefore, as for conventional marketing theories (Oliver, 1997), some authors consider satisfaction and quality as different frameworks (Yoon \& Uysal, 2005). A mainstream section of service marketing literature considers satisfaction as an affective effect that derives from cognitive outcomes to quality perception which follows service experiences.

Although the main theoretical approach considers satisfaction as an effect of service quality (Brady, Cronin \& Brand, 2002), Bolton and Drew (1991) positioned satisfaction before service quality. Moreover, while Parasuraman, Zeithaml, and Berry (1994) assessed that the path of such link leans on the fact that measurements may be done at a general or at a transaction level, another study affirms that the service satisfaction/quality/behavioral purpose model may function in the two levels (Brady, Knight, Cronin, Tomas, Hult, \& Keillor, 2005).

Tourism literature generally considers the mainstream quality/affects/satisfaction perspective and assesses that the quality's performance is sustained in the backgrounds of attractions at a tourist destination (Chen \& Tsai, 2007). More precisely, some authors assess that perceived service quality impacts visitors' satisfaction (Lee et al., 2007) whilst others distinguish among "push motivations" (tourist emotions, impulses, animations, etc.) which straight impact visitors' loyalty to a destination, and "pull motivations" (linked to the features of a destination) which straight impact visitor’s satisfaction (Yoon \& Uysal, 2005).

Taking into account such theoretical framework, this paper argues that the location of an exhibition (represented by an appealing tourist destination) enhances the perceived quality of the exhibition intended as a service provided by the museum. Therefore, the location impacts visitor's satisfaction.

In literature, consumer's behavior is generally observed through the cognitive/affective/conative model (Lam, Shankar, Erramilli, \& Murthy, 2004). Authors state that the cognitive element goes before emotional effects (Chiou \& Droge, 2006). At the same time, some studies assess that emotional effects guide consumer's behavior. In fact, affective satisfaction intercedes with the response of cognitive service quality on conative 
consumer behavior (Cole \& Illum, 2006; Dabholkar, Sheperd, \& Thorpe, 2000). Thus, the relationship between perceived quality and fidelity is in part influenced by general satisfaction. Moreover, service quality, satisfaction, and service value all straightly influence consumer's behavior when evaluated jointly (Brady et al., 2005). In the midst of these concepts, satisfaction brings the most forceful influence on behavior, followed by service quality and service value. However, satisfaction and service value also influence the relationship between perceived service quality and consumer's behavior.

For the aim of this research, this paper considers consumer's behavior as the degree of the willingness-to-pay the exhibition ticket. Such degree depends whether the exhibition itself is located in an appealing tourist location or not. In conclusion, this study assesses that the appealing location of an exhibition impacts the service (the exhibition) perceived quality, affects the overall visitor's satisfaction, and influences visitor's behavior in terms of willingness-to-pay the exhibition ticket. Based on this background, this paper suggests that the perceived quality of a destination/location's features directly positively influences visitor's behavior, and that visitor's satisfaction is positively connected to visitor's behavior.

\section{Emotions, Satisfaction, and Consumer's Behavior}

As previously stated, marketing literature has assessed that emotions should be considered as important factors in the conceptualization of consumer's satisfaction (Oliver, 1997; Wirtz et al., 2000); moreover, in order to understand visitor's satisfaction, tourism management and tourism marketing scholars have evidenced how emotional assets must be analyzed alongside with cognitive assets (Zins, 2002). In particular, Russel and Pratt (1980) have identified two major dimensions of emotions, such as pleasure and arousal: the first dimension indicates the degree of enjoyment of an individual who lives a specific circumstance; the second dimension indicates the degree of motivation and dynamism of an individual who lives in a specific circumstance.

For the aim of this study therefore taking into account arts management, arts marketing, and cultural tourism issues, when the topic relates to the particular case of museums exhibitions, both dimensions (pleasure and arousal) appear to be significant. In fact, in order to demonstrate that an attractive destination/location for an exhibition may function as a strategic tool to attract visitors, it is useful to take into account some features of tourists and visitors, which refer both to pleasure and to arousal.

Observing museums, there is evidence that tourists enhance their desire to visit museums when abroad and when based on an attractive tourist destination (McIntyre, 2007; Prentice, 2001). In other terms, they are more dynamic and motivated. Literature also assesses that tourists that visit museums based on an appealing tourist destination are already predisposed to do so (Harrison, 1997). At the same time, other studies show that tourists under the specific circumstance which consists in visiting an appealing destination feel well and are happy (Dolnicar, 2002). Moreover, researches show that highly motivated individuals will assumingly engage at a deeper level with cultural attraction and, as a consequence, will have a more meaningful and emotional experience. Thus, in order to let the visitor experience happiness and pleasure, if a museum's objectives include the stimulation of the visitors' motivations and the enhancement of their knowledge, such museum will certainly attract more visitors. This paper argues that a museum, in order to enhance such approach, should strategically take into account the fact that to be based on an attractive tourist destination might help. On the basis of paper's assumptions, in fact, an attractive location enforces visitor's satisfaction.

Literature has identified a connection between the happiness perceived throughout the consumer's experience and the achieved consumer's satisfaction. Taking into account tourism management literature, 
scholars have agreed that with the enhancement of happiness felt by tourists when visiting a destination, there is an improvement of their levels of satisfaction (Westbrook \& Oliver, 1991; Wirtz \& Bateson, 1999). Therefore, an appealing tourist destination should enforce such happiness. With the aim to observe satisfaction, Woodruff, Cadotte, and Jenkins (1983) have evidenced a positive connection between disconfirmation and emotions. Nevertheless, in tourism management literature, the connection between disconfirmation and happiness is not easy to find and the disconfirmation itself appears to be more related to the perceived quality (Bigné, Andreu, \& Gnoth, 2005). Therefore, the perceived quality seems representing the principal source of visitors' emotions such as happiness. This paper then firstly argues that there is a positive correlation between the emotional experience (linked to the degree of happiness) and the cognitive experience (linked to the degree of perceived quality). Therefore, perceived quality positively affects happiness feelings and happiness feelings affect visitor's satisfaction. Secondly, this study argues that if an appealing location affects the degree of perceived quality, in order to enhance visitors' happiness feelings and visitors' satisfaction, museum or a museum's exhibition should be based on an attractive tourist destination.

Moreover, literature that has studied services and satisfaction has stated that satisfaction influences the desire to replicate the purchase and affects the post-purchase behavior (Keaveney, 1995; Oliver \& Swan, 1989; White \& Yu, 2005). Therefore, visitor's satisfaction influences the motivation of the exhibition visit, this being intended, for instance, as its willingness to pay the entrance ticket. In the framework of museums and museums' exhibitions, such statement might be identified as a more intense desire and willingness to buy a ticket for an exhibition when such exhibition is located in an attractive location which is represented by an appealing tourist destination.

Therefore, the location of the exhibition directly affects the intensification of the exhibition experience, evaluated as visitor's aptitude in buying the ticket of the exhibition. This will generate for the museum an economic surplus. Moreover, it is expected that satisfied visitors will more intensively feel the exhibition experience and, for instance, will be more engaged and more interested in the exhibition itself. In sum, with an increase of the degree of visitor's satisfaction, it is possible to see an enhancement of the degree of visitors' engagement and motivation.

In order to quantify the impact of an appealing location in the framework of an exhibition, this paper considers the appealing location as a "change" in an attribute of the exhibition in monetary terms. Finally, in order to reveal the trade-offs among its attributes in terms of total revenue determinants of visitor demand in generating an economic surplus or shortfall, this study uses a new coefficient for the economic valuation of the "Venice and Islam 828-1797".

\section{Research Methods}

\section{Preference Model}

By a broad use of the study of Mariani and Mussini (2013), it is possible to declare that, in general, studies investigating willingness-to-pay for environmental or cultural goods use either contingent valuation method or discrete choice experiment as the stated preference elicitation technique (Boxall, Adamowicz, Swait, Williams, \& Louviere, 1996; Bille-Hansen, 1997; Sanz, Herrero, \& Betade, 2003; Mazzanti, 2003).

The focus is on ranking scale and opts for a very general preference model used in traditional conjoint analysis (CA). In fact, this paper exploits the information contained in the ranking conjoint format by regressing the individual responses on a piece-wise linear function of all the attribute levels which describe the good in 
question. Since conjoint data are collected on a nonmetric scale, a nonmetric estimation procedure like a monotone regression that involves a monotonic transformation of the dependent variables (MONANOVA) would be more appropriate than ordinary least-squares regression (OLS) multiple regressions; however, as demonstrated by Carmone, Green, and Jain (1978) and Cattin and Wittink (1982), the OLS regression provides similar parameter estimates for both ranking and rating scales, therefore it seems a reliable estimation procedure. This function is defined as follows:

$$
U_{k}=\sum_{i=0}^{n} \beta_{i} x_{i k}
$$

where $x_{0}$ is equal to 1 and $n$ is the number of all levels of the attributes which define the combination of a given good. Each variable $x_{i j}$ is a dichotomous variable which refers to a specific attribute level, and it equals 1 if the corresponding attribute level is present in the combination of attributes, which describes the alternative $k$, otherwise that variable is 0 . As a result, the utility associated with alternative $k\left(U_{k}\right)$ is obtained by summing the terms $\beta_{i} x_{i k}$ over all attribute levels; where $\beta_{i}$ is the partial change in $U_{k}$ for the presence of the attribute level $i$, holding all other variables constant. This study refers to this piece-wise linear function as a part-worth function model which gives a specific utility value for each level of the considered attributes, usually referred to as part-worth utility. As a consequence, the number of parameters estimated by assuming the part-worth specification is larger than that required by alternative preference model specifications, such as the vector model form and the ideal model.

\section{The Coefficient of Economic Valuation}

Having chosen the preference model (and the ranking scale), this paper then proceeds to use a coefficient of economic re-evaluation for a hypothetical change that occurs in the combination of the attribute levels. Taking into account the study of Mariani and Mussini (2013), this paper introduces the following notation:

- Let $b$ be the current profile (hereafter, status quo) of the good or service;

- Let $i$ (with $I=1, \ldots, n$ ) be the alternative profile which differs from $b$ for the attribute level $i$;

- Let $U_{b}$ denote the sum of the part-worth utilities associated with the status quo of the good or service;

- Let $U_{i}$ denote the sum of the utility scores associated with the alternative profile $i$.

It is possible to calculate the total utility variation, obtained by replacing one attribute level of the status quo $b$ with the attribute level $i$, that is when passing from the status quo $b$ to the alternative profile $i . M_{i}$ indicates the ratio, which results by dividing the difference between the total utility of the alternative $i$ and the status quo one by the total utility of the status quo, formally:

$$
M_{i}=\frac{U_{i}-U_{b}}{U_{b}}
$$

where $U_{b}$ is assumed to be different from 0 . The ratio in equation (2) indicates whether the status quo modification generates a loss or a gain in term of total utility. It is evident that a zero value for $M_{i}$ represents the indifferent situation between loss and gain in terms of total utility. However, the utility modification arising from an attribute level modification can be considered more or less important by respondents. Consequently, such an attribute level modification can have a more important economic impact than a utility modification which has a similar intensity but involves a less relevant attribute. 
As a solution, this paper proposes to weigh $M_{i}$ by the relative importance of the modified attribute. The range of the utility values (from highest to lowest) for each attribute provides an indicator of how important the attribute is compared to the remaining attributes. Attributes with larger utility ranges play more important roles than those with smaller ranges. For any attribute $j$, the relative importance can be computed by dividing its utility range by the sum of all utility ranges as follows:

$$
I_{j}=\frac{\max \left(W_{j}\right)-\min \left(W_{j}\right)}{\sum_{j=1}^{J}\left[\max \left(W_{j}\right)-\min \left(W_{j}\right)\right]}
$$

where $J$ is the number of attributes and $W_{j}$ is the set of part-worth utilities referred to the various levels of attribute $j$. Usually, the important values are represented as percentages and have the property of summing to one hundred. Otherwise, it is possible to express these important values in terms of decimal fractions whose sum is one. If this is the case, entering the importance of the modified attribute in equation (2), the coefficient formulation becomes:

$$
M I_{i j}=M_{i} * I_{j}
$$

Since $U_{b}$ can be negative, the general formulation of the coefficient is:

$$
M I_{i j}= \begin{cases}\frac{U_{i}-U_{b}}{U_{b}} * I_{j} & U_{b}>0 \\ \frac{U_{b}-U_{i}}{U_{b}} * I_{j} & U_{b}<0\end{cases}
$$

It is possible to use equation (5) for estimating the variation of the total revenue generated by assuming a change in the status quo profile. Given the total revenue associated with the status quo profile, $\pi$, the coefficient of economic re-evaluation is expressed as follows:

$$
V_{i j}=M I_{i j} * \pi
$$

where $V_{i j}$ denotes the amount of the revenue variation. Revenue variation in equation (6) is obtained by supposing that the monetary attribute referred to a non-market good (price or admission charge) varies in proportion to the change in total utility of that good.

Although this assumption seems restrictive, this study argues that if the monetary amount asked to a user (the visitor) concerning a non-market good (the exhibition) reflecting on how that user values the combination of attributes of the good in terms of utility, it is credible to assess the economic value of a change in the combination of attributes as a function of the utility and importance of the modified attribute. In addition, it is possible to notice that CA serves the scope of approximating the real structure of preferences, given that only a partial knowledge of preferences can be known. Therefore, this paper suggests using the coefficient of economic re-evaluation as a monetary indicator, which approximates the impact of a given utility change in monetary terms.

\section{Application to an Exhibition}

The path of the exhibition begins with the legendary transfer of San Marco's corpse from Alexandria to Venice (827) and continues to the end of the "doge” era in 1797, which was hosted in Venice itself in the 
symbolic Doge's Palace, after Paris and New York. In this large-scale exhibition on the relationship between Venice and the world of Islam, many of the exhibited works were rented by European and American museums and some private Venetian collections.

Institut du Monde Arabe in Paris, Metropolitan Museum of Art in New York, and Musei Civici Veneziani worked together to produce this exhibition that consisted of various sections illustrating different chronological phases and topics of the millenary relationship between the Venetian and Islamic civilizations.

\section{Survey Design and Data Collection Method}

Data were collected by using face-to-face interviews in which each respondent was asked to rank alternatives included a set of choices presented within a questionnaire ${ }^{1}$.

Starting from a full factorial, which comprises $(2 \times 2 \times 2 \times 3=24)$ profiles, it created a fractional factorial design for main-effects, which included eight profiles (Addelman, 1962). The alternatives included in this set were taken from a full factorial design produced by a permutation of all the attribute levels. Each alternative is described by four attributes: admission charge (three ticket levels), location (Venice or in a different place), modality of gathering information about the exhibition (provided to visitors by organizers and information gathered by visitors autonomously), and additional information services (presence or absence of additional multimedia services). The sample comprises 501 respondents who were interviewed after the visit.

\section{Research Results}

In the paper's sample, one third of the visitors $(N=147)$ reported being completely or partially agree to have visited the exhibition just because the location was Venice. At the same time, two out of three of 294 respondents would still have visited the exhibition in a different location. Sixty visitors said the location was indifferent.

After dividing the interviewed visitors into two groups, taking into account if they did agree or not to the sentence "I visited this exhibition just because it's in Venice", the total respondents become 441 units (Table 1).

The profile of the visitors of the exhibition shows that $59.0 \%$ are women. In most cases, they are more than 45 years of age; the modal age group (28.6\%) is 55-64, while young people up to 24 are $5.9 \%$. One third of the sample is foreign national (not Italian) and its level of education is postgraduate degree, degree, or first degree. In most of the cases, they are employees (27.9\%) and only 7.3\% are students. Overall, they were satisfied with the exhibition (92.7\%).

One in three visited the exhibition influenced by the fact that it was in Venice. Especially males (35.91\%) were more in agreement with this question than women (31.54\%). The proponents of Venice have a higher age (the classes $<35-44>$ and $<$ over $55>$ are better represented), a high level of education (34.4\% with postgraduate degree, degree, or first degree), and $42.2 \%$ are foreigners. For pensioners, it has been reached the value of $50.8 \%$ and $28.1 \%$ for students.

Young people, up to 34 years, as well as the middle class of age (45-54 years old), are less influenced by the location. Women are less in agreement (31.5\%), as well as more generally Italian visitors (28.9\%). The level of

\footnotetext{
1 The questionnaire was divided into four sections. In the first section, the respondent was asked to give the reasons that induced him/her to visit the exhibition and to describe the visit through a series of either bundled or unbundled questions. In the second section, the respondent gave answers about the sources of information used to gather information concerning the exhibition. Furthermore, in this section, the respondent could express a judgment concerning the use of complementary services to be implemented in the visit in accordance with his/her experience. In the third section, the respondent was asked to rank a set of alternatives concerning the arrangement of the exhibition. The last section was devoted to collecting information on the socio-economic characteristics of the respondent.
} 
education is up to secondary school diploma (31.3\%) and the profession is entrepreneur (28.7\%), employee (30.1\%), teacher (29.5\%), and student (28.1\%).

Table 1

"I Have Visited the Exhibition Just Because It's in Venice"

\begin{tabular}{|c|c|c|c|c|c|}
\hline & & $\begin{array}{l}\text { \% row } \\
\text { agree }\end{array}$ & $\begin{array}{l}\text { \% row } \\
\text { do not agree }\end{array}$ & $\%$ column & $N$. \\
\hline \multirow{6}{*}{ Age (years) } & Up to 24 & 23.08 & 76.92 & 5.90 & 26 \\
\hline & $25-34$ & 26.53 & 73.47 & 11.11 & 49 \\
\hline & $35-44$ & 34.38 & 65.63 & 14.51 & 64 \\
\hline & $45-54$ & 29.41 & 70.59 & 23.13 & 102 \\
\hline & $55-64$ & 39.68 & 60.32 & 28.57 & 126 \\
\hline & 65 or more & 35.14 & 64.86 & 16.78 & 74 \\
\hline Total & & & & 100.00 & 441 \\
\hline \multirow{2}{*}{ Gender } & Male & 35.91 & 64.09 & 41.04 & 181 \\
\hline & Female & 31.54 & 68.46 & 58.96 & 260 \\
\hline Total & & & & 100.00 & 441 \\
\hline \multirow{2}{*}{ Citizenship } & Italian & 28.91 & 71.09 & 66.67 & 294 \\
\hline & Foreign national & 42.18 & 57.82 & 33.33 & 147 \\
\hline Total & & & & 100.00 & 441 \\
\hline \multirow{2}{*}{$\begin{array}{l}\text { Educational level } \\
\text { (completed) }\end{array}$} & Postgraduate degree/degree or first degree & 34.35 & 65.65 & 66.67 & 294 \\
\hline & Up to secondary school diploma & 31.29 & 68.71 & 33.33 & 147 \\
\hline Total & & & & 100.00 & 441 \\
\hline \multirow{6}{*}{ Job } & $\begin{array}{l}\text { Entrepreneur/ } \\
\text { freelance professional }\end{array}$ & 28.74 & 71.26 & 19.73 & 87 \\
\hline & Employee & 30.08 & 69.92 & 27.89 & 123 \\
\hline & Teacher/professor & 29.49 & 70.51 & 17.69 & 78 \\
\hline & Pensioner & 50.79 & 49.21 & 14.29 & 63 \\
\hline & Student & 28.13 & 71.88 & 7.26 & 32 \\
\hline & Other & 36.21 & 63.79 & 13.15 & 58 \\
\hline Total & & & & 100.00 & 441 \\
\hline \multirow{2}{*}{$\begin{array}{l}\text { Overall. Have you been } \\
\text { satisfied with this experience? }\end{array}$} & Satisfied & 34.55 & 65.45 & 92.71 & 356 \\
\hline & Not satisfied & 28.57 & 71.43 & 7.29 & 28 \\
\hline Total & & & & 100.00 & 384 \\
\hline
\end{tabular}

Source: own calculations on data provided by the "Fondazione di Venezia".

\section{Discussion}

Data show slight differences but open up some reflections:

- those who consider Venice as an added value for the location result within a profile which is more tourism-oriented than cultural exhibition-oriented having a profile more like a tourist than like a person interested in the exhibition; the presence of cruise passengers could influence the selection of the visitors, who may find the ticket of the exhibition in the holiday package;

- those who consider the cultural/didactic aspects of the exhibition have a profile of induced choice. Young, Italian (probably in Venice just for the exhibition), with a high level of education considering the age, teacher, or student (school trip); 
- those who consider the exhibition as a whole unique meaning (Venice $=$ culture) have a profile of awareness of choice. They are professionals or employees, aged between 45 and 54 years old.

The satisfaction of the experience of visiting the exhibition seems to depend on location. In the sample, $92.7 \%$ of visitors were fully or partially satisfied. Among those who visited the exhibition because it took place in Venice, $34.6 \%$ were satisfied and $28.6 \%$ not satisfied.

This is the global framework, it is now calculated the corresponding revenue variation by using the coefficient of economic valuation when changes in the status quo are hypothesized. This paper starts now estimating part-worth utilities and the relative importance for each attribute and uses these estimates to obtain a valuation of revenue variation associated with a change in the combination of the attributes describing the exhibition in question. The study estimates the part-worth utilities using OLS, and shows the relative importance assigned to the corresponding attribute at the first place, it found the price after information during the exhibition, venue in Venice and general information before the exhibition. It also reported the utilities for Venice attribute level (Table 2).

Table 2

Part-Worth Utilities and Attribute Importance Values

\begin{tabular}{lll}
\hline Attribute level & Part-worth utility & Attribute importance \\
\hline Venue: Venice & 0.692 & 0.23526 \\
Venue: Other place & -0.692 & 0.13948 \\
Inf. concerning the exhibition & & 0.24974 \\
Additional inf. services & & 0.37552 \\
Admission charge & & \\
Intercept & 4.183 & \\
$U_{b}$ & 3.953 & \\
$U_{i}$ & 2.569 & \\
\hline
\end{tabular}

Source: own calculations on data provided by the "Fondazione di Venezia".

Visitors prefer the venue in Venice rather than in a different place and seem more interested in collecting information about the exhibition autonomously and with a preference to the provision of additional multimedia services, which makes the exhibition easier to understand. Table 1 also presents the importance for each attribute.

The most important attribute in terms of relative importance is the admission fee when modality of gathering information appears as the least relevant attribute whereas location and additional multimedia services show a similar level of relative importance.

In accordance with the Mariani coefficient, the part-worth utilities and relative importance values can be used to estimate revenue variation generated by the change in the status quo (Venice; information concerning the exhibition induced; additional information services absent).

Therefore, it computed the total utility associated with the status quo by summing the part-worth utilities of the corresponding attribute levels. It is possible to hypothesize any change in the status quo combination of the attribute levels and calculate the total utility assigned to that alternative.

In Table 3, row 1 outlines the combination of attribute levels specifying the actual exhibition (status quo). If it hypothesized that the revenue generated by this status quo is EUR 100,000.00 ( $\pi$ ), it is possible to estimate the revenue variation induced by a single attribute level change as shown in Table 3 . That revenue decreases if the venue changes (EUR -6,326.00). 
Table 3

Economic Re-evaluation by Changing a Non-monetary Attribute

\begin{tabular}{llll}
\hline Status quo & Modification of attribute $j$ & Number of observations & $V_{i j}$ \\
\hline Venue in Venice & Other place & 501 & $-6,326.00$ \\
Unsatisfied & & 216 & $-5,291.91$ \\
Satisfied & & 158 & $-7,597.48$ \\
\hline
\end{tabular}

Source: own calculations on data provided by the "Fondazione di Venezia".

This paper also investigates how the degree of visitor's satisfaction affects the preference structure in monetary terms. Two sub-groups have been created: a group composed of 158 satisfied visitors and another group of 216 unsatisfied visitors ${ }^{2}$. This paper aims to assess the effect of visitor's satisfaction on the revenue variation induced by changing the attribute combination. Thus, it is possible to calculate the coefficient of re-evaluation for both groups (Table 3). That revenue variations are smaller (EUR -5,291.91) for unsatisfied visitors (for satisfied the value is EUR -7,597.48).

In this case, the monetary attribute's relative importance definitely exceeds the importance values of the other non-monetary attributes. This reduces the impact of a utility change generated by modifying a non-monetary attribute on the revenue variation.

\section{Conclusions}

Results suggest that choosing Venice as the location for the exhibition generates the larger gain in terms of total revenue variation, $6.3 \%$ of total revenue. The reason is that Venice represents an appealing tourist destination, for a third of the visitors, the location was important.

However, this study has shown how determinants of demand for the exhibition vary in accordance with actual visitor's opinion on the admission charge required for attending the exhibit. More specifically, when visitors believe that the admission charge is too high, the hypothetical revenue variations are smaller than for people who are happy with the price.

This study has esteemed visitor's willingness-to-pay in the Venice-located exhibition by exploiting all the information collected in a ranking or rating conjoint response format. In fact, this methodology may provide cultural managers and cultural events organizers with information on determinants of revenue variation. In order to answer the question of which determinants are the key drivers of visitor's behavior and business performance, the relationship between quality and satisfaction turns to be useful for both researchers and cultural managers.

The perceived quality of an appealing destination's offerings detained the cognitive aspects of consumer's behavior. The visitor's satisfaction framework encompasses both cognitive (e.g. the information used to gather information concerning the exhibition; the use of complementary services; the arrangement of the exhibition, etc.) and emotional aspects (the location), while the behavioral framework (the willingness-to-pay) represents the conative feature of visitor's behavior.

In sum, the location/tourist destination image is linked to the exhibition quality, to satisfaction, and to customer's behavior. In other words, an attractive tourist destination mediates the relationship between

\footnotetext{
${ }^{2}$ A number of visitors (111) attended the exhibition with a cut price ticket or a complimentary ticket, the authors then excluded them from the sample.
} 
exhibition quality and satisfaction, which translates into visitor's behavior or willingness-to-pay. In addition, visitor's behavior is directly related to tourist destination feeling and tourist destination attributes determine the perceived quality and satisfaction of an exhibition/museum's offering. Cultural organizations and cultural managers should then consider the most profitable way to invest in a new museum or in a cultural event, which is located in an attractive tourist destination. The expansion of the cultural tourism sector and improved accessibility of tourist destinations are enhancing competitiveness for cultural managers. Even though a museum comprises various particular cognitive and affective features, museums' visitors might take into account the location and consider the museum and its location as a single entity. Therefore, a visitor's satisfaction results from different cognitive and affective experiences involving various determinants that jointly establish the visitor's perception of the exhibition's attributes. For the satisfied ones, Venice is $7.6 \%$ of turnover, while the value for a few dissatisfied ones is $5.3 \%$.

Understanding what drives visitor's satisfaction in a cultural organization represents a good foundation for increasing customer's retention. Moreover, the choice (and the valorization) of the location represents a fundamental input for any cultural organization strategy development and managerial improvements.

\section{References}

Addelman, S. (1962). Symmetrical and asymmetrical fractional factorial plans. Technometrics, 4(1), 47-58.

Bagozzi, R. P., Gopinath, M., \& Nyer, P. (1999). The role of emotions in marketing. Journal Academy of Marketing Science, 27(2), 184-206.

Belk, R. W., \& Wallendorf, M. (1989). The sacred and profane in consumer behavior: Theodicy on the Odyssey. Journal of Consumer Research, 16, 1-33.

Bigné, J. E., Andreu, L., \& Gnoth, J. (2005). The theme park experience: An analysis of pleasure, arousal and satisfaction. Tourism Management, 26(6), 833-844.

Bille-Hansen, T. (1997). The willingness-to-pay for the Royal Theatre in Copenhagen as a public good. Journal of Cultural Economics, 21, 1-28.

Bolton, R. N., \& Drew, J. H. (1991). A longitudinal analysis of the impact of service changes on customer attitudes. Journal of Marketing, 55(1), 1-10.

Boxall, P., Adamowicz, W., Swait, J., Williams, M., \& Louviere, J. (1996). A comparison of stated preference methods for environmental valuation. Ecological Economics, 18, 243-253.

Brady, M. K., Cronin, J. J., \& Brand, R. R. (2002). Performance-only measurement of service quality: A replication and extension. Journal of Business Research, 55, 17-31.

Brady, M. K., Knight, G. A., Cronin, J. J., Tomas, G., Hult, M., \& Keillor, B. D. (2005). Removing the contextual lens: A multination, multi-setting comparison of service evaluation models. Journal of Retailing, 81(3), 215-230.

Caldwell, N. (2002). Rethinking the measurement of service quality in museums and galleries. International Journal of Nonprofit and Voluntary Sector Marketing, 7(2), 161-171.

Carmone, F. J., Green, P. E., \& Jain, A. K. (1978). Robustness of conjoint analysis: Some Monte Carlo results. Journal of Marketing Research, 15, 300-303.

Cattin. R. G., \& Wittink, R. (1982). Commercial use of conjoint analysis: A survey. Journal of Marketing, 46, 44-53.

Chakrapani, C. (1998). How to measure service quality \& customer satisfaction: The informal guide for tools and techniques. Chicago, American Marketing Association.

Chen, C. F., \& Tsai, D. (2007). How destination image and evaluative factors affect behavioral intention? Tourism Management, $28,1115-1122$.

Chiou, J. S., \& Droge, C. (2006). Service quality, trust, specific asset investment, and expertise: Direct and indirect effects in a satisfaction-loyalty network. Journal of the Academy of Marketing Science, 34(4), 613-627.

Colbert, F. (2003). Entrepreneurship and leadership in marketing arts. International Journal of Arts Management, 6(1), 30-39.

Cole, S. T., \& Illum, S. F. (2006). Examining the mediating role of festival visitors' satisfaction in the relationship between service quality and behavioral intentions. Journal of Vacation Marketing, 12(2), 160-173. 
Dabholkar, P. A., Sheperd, C. D., \& Thorpe, D. I. (2000). A comprehensive framework for service quality: An investigation of critical conceptual and measurement issues through a longitudinal study. Journal of Retailing, 76(2), 139-173.

Dolnicar, S. (2002). Activity-based market sub-segmentation of cultural tourists. Journal of Hospitality and Tourism Management, 9(2), 94-105.

Gerson, R. F. (1994). Measuring customer satisfaction. London: Kogan Page.

Harrison, J. (1997). Museums and touristic expectations. Annals of Tourism Research, 24(1), 23-40.

Harrison, P., \& Shaw, R. (2004). Consumer satisfaction and post-purchase intentions: An exploratory study of museum visitors. International Journal of Arts Management, 6(2), 23-33.

Herreman, Y. (1998). Museums and tourism: Culture and consumption. Museum International, 50(3), 4-12.

Keaveney, S. M. (1995). Customer switching behaviour in service industries. An exploratory study. Journal of Marketing, 59(2), 71-82.

Kirchenblatt-Gimblett, B. (1998). Destination culture: Tourism, museums, and heritage. Berkeley, Los Angeles, London: University of California Press.

Lam, S. Y., Shankar, V., Erramilli, M. K., \& Murthy, B. (2004). Customer value, satisfaction, loyalty, and switching costs: An illustration from a business-to business service context. Journal of the Academy of Marketing Science, 32(3), 293-311.

Lee, S. Y., Perick, J. F., \& Crompton, J. (2007). The roles of quality and intermediary constructs in determining festival attendees' behavioral intention. Journal of Travel Research, 45(4), 402-412.

Mariani, P., \& Mussini, M. (2013). A new coefficient of economic valuation based on utility scores. Argumenta Oeconomica, $30(2), 33-46$.

Mazzanti, M. (2003). Discrete choice model and valuation experiment. Journal of Economic Studies, 30(6), 584-604.

McIntyre, C. (2007). Survival theory: Tourist consumption as a beneficial experiential process in a limited risk setting. International Journal of Tourism Research, 9(2), 115-130.

McKercher, B. (2004). A comparative study of international cultural tourists. Journal of Hospitality and Tourism Management, 11(2), 95-107.

Oliver, R. L. (1997). Satisfaction. A behavioral perspective on the consumer. New York: McGraw-Hill.

Oliver, R. L., \& Desarbo, W. S. (1988). Response determinants in satisfaction judgments. Journal of Consumer Research, 14(4), 495-507.

Oliver, R. L., \& Swan, J. E. (1989). Equity and disconfirmation perceptions as influences on merchant and product satisfaction. Journal of Consumer Research, 16(3), 372-383.

Parasuraman, A., Zeithaml, V. A., \& Berry, L. L. (1994). Reassessment of expectations as a comparison standard in measuring service quality: Implications for further research. Journal of Marketing, 58, 111-124.

Philips, D., \& Baumgartner, H. (2002). The role of consumption emotions in the satisfaction response. Journal of Consumer Psychology, 12(3), 243-252.

Prentice, R. (2001). Experiential cultural tourism: Museums \& the marketing of the new romanticism of evoked authenticity. Museums Management and Curatorship, 19(1), 5-26.

Russel, J., \& Pratt, G. (1980). A description of the affective quality attributed to environments. Journal of Personality and Social Psychology, 38(2), 311-322.

Sanz, J. A., Herrero, L., \& Betade, A. M. (2003). Contingent valuation and semiparametric methods: A case study of the national museum of sculpture in Vallaloid, Spain. Journal of Cultural Economics, 27, 241-257.

Silberberg, T. (1995). Cultural tourism and business opportunities for museums and heritage sites. Tourism Management, 16(5), 361-365.

Truong, T. H., \& Foster, D. (2006). Using HOLSAT to evaluate tourist satisfaction at destinations: The case of Australian holidaymakers in Vietnam. Tourism Management, 27, 842-855.

Tufts, S., \& Milne, S. (1999). Museums: A supply-side perspective. Annals of Tourism Research, 26(3), 613-631.

Vida, I., \& Reardon, J. (2008). Domestic consumption: Rational, affective or normative choice? Journal of Consumer Marketing, 25(1), 34-44.

Westbrook, R. A., \& Oliver, R. L. (1991). The dimensionality of consumption emotion patterns and consumer satisfaction. Journal of Consumer Research, 18(1), 84-91.

White, C., \& Yu, Y. T. (2005). Satisfaction emotions and consumer behavioral intentions. The Journal of Services Marketing, 19(6/7), 411-420. 
Wirtz, J., \& Bateson, J. E. G. (1999). Consumer satisfaction with services: Integrating the environment perspective in service marketing into traditional disconfirmation paradigm. Journal of Business Research, 44(1), 55-66.

Wirtz, J., Mattila, A. S., \& Tan, R. L. P. (2000). The moderating role of target-arousal on the impact of affect on satisfaction. An examination in the context of service experience. Journal of Retailing, 76(3), 234-250.

Woodruff, R. B., Cadotte, E. R., \& Jenkins, R. L. (1983). Modeling consumer satisfaction processes using experience-based norms. Journal of Marketing Research, 20(3), 296-304.

Yoon, Y., \& Uysal, M. (2005). An examination of the effects of motivation and satisfaction on destination loyalty: A structural model. Tourism Management, 26, 45-56.

Zins, A. H. (2002). Consumption emotions experience quality and satisfaction: A structural analysis for complainers versus no complainers. Journal of Travel and Tourism Marketing, 12(2/3), 3-18.

Churchill, G. A. Jr., \& Surprenant, C. (1982). An investigation into the determinants of customer satisfaction. Journal of Marketing Research, 19, 491-504. 